\title{
Análisis del tratamiento de la mujer en la prensa española. Día Internacional de las Mujeres ${ }^{1}$
}

\author{
María GÓMEZ Y PATIÑO \\ Universidad de Zaragoza \\ mariagp@unizar.es
}

Recibido: 28/06/2010

Aceptado: 16/12/2011

\begin{abstract}
Resumen
El presente trabajo expone el análisis y evaluación del tratamiento que los medios de comunicación escritos dan al Día Internacional de las Mujeres. El estudio enfoca seis puntos de vista y los resultados de todos ellos, es decir la suma de lo cuantitativo y lo cualitativo junto con los efectos de la formación de la agenda periodística o los publicitarios y/o humorísticos, permiten conocer la posición de la mujer en la prensa diaria escrita en el ámbito nacional. Las conclusiones y sus interpretaciones permiten discutir el lugar que la mujer merece, aunque sólo sea un día al año, o si por el contrario cabría desear que este espacio ocupado por un día, debería ser espacio dedicado cada día del año, quizá no una forma diferenciada, pero sí constante y estable.
\end{abstract}

Palabras clave: Género, Agenda setting, efectos de los medios, Día Internacional de las Mujeres.

\section{Analysis of women's treatment in Spanish press. Women's International Day}

\begin{abstract}
This work describes the analysis and evaluation of the journalistic treatment that mass media devote to Women's International Day. This study focuses on six points. The results of all of them, this is the conjunction of qualitative and qualitative characteristics together with the effects produced by selection of the journalistic agenda or the effects produced by publicity or humour allow the know the position of women within the everyday national written press. The conclusions and their interpretations is the space for discussion: if the place occupied by women is the deserved space or if on the contrary this place should be occupied by women every single day in the year either as an emergent item or one regular and stable one.
\end{abstract}

Key words: Gender, Agenda setting, Mass media effects, Women's International Day.

\section{Referencia normalizada}

GÓMEZ PATIÑO, María (2011): “Análisis del tratamiento de la mujer en la prensa española. Día Internacional de las Mujeres”. Estudios sobre el mensaje periodístico. Vol. 17, núm. 1, págs.: 119-140. Madrid, Servicio de Publicaciones de la Universidad Complutense.

Sumario: 1. Introducción. 2. Objetivo. 3. Corpus de investigación. 4. Metodología. 5. Aplicación metodológica. 6. Discusión y conclusiones. 7. Referencias biblográficas.

\footnotetext{
${ }^{1}$ Se ha optado por titular el trabajo recogiendo la última denominación que la ONU dio a esta jornada hace ya algunos años: Día Internacional de las Mujeres, tal como refleja el anuncio de publicidad institucional insertado en los medios analizados, y no como de forma relajada se viene denominando: Día Internacional de la Mujer Trabajadora.
} 


\section{Introducción}

Los medios de comunicación, además de ejercer como notarios de la realidad social son, en buena medida, un reflejo del sentir popular, en general, y de la población lectora en particular, lo que constituye un termómetro muy valioso para conocer la realidad social, de forma documentada. Este trabajo incide en el tratamiento periodístico que hace la prensa nacional en el Día Internacional de las Mujeres Trabajadoras, es decir, el 8 de marzo de $2007^{2}$ (en adelante 8-M). Esta investigación permite tener una visión objetiva del tema. Trata de analizar "lo publicado" en torno a la mujer, en su día internacional. La selección del corpus para la investigación, la recogida de material, su posterior análisis y evaluación ha posibilitado tener una visión ajustada a la realidad social del objeto estudiado, es decir, los medios de comunicación impresos, o periódicos diarios, es decir material documentable, con resultados contrastables y verificables. Resultó una circunstancia particular poder estudiar el tratamiento que los medios de comunicación impresos dieron al Día 8-M en el año 2007, reconocido como el Año Europeo de la Igualdad, y en cuya víspera, el 7-3-2007 fue aprobada la Ley de Igualdad, calificada de muy avanzada en el ámbito jurídico europeo e internacional. El hecho de que internacionalmente se confiera al tema de la mujer trabajadora tanta importancia, se le otorgue un día conmemorativo y se organicen infinidad de actos, eventos, reuniones, celebraciones, etc., informan de que a pesar de cubrir un espacio informativo muy importante, $a$ priori no se puede definir la naturaleza del tema. Cabe preguntarse si se trata de una noticia; de efemérides; de un item de la agenda periodística y política; o un ítem emergente, temporal y abierto.

La noción de noticia resulta ambigua, considerando que el concepto general de noticia es la información nueva. El hecho de que se celebre el 8-M no constituye un tema nuevo, aunque sí puede ser nuevo en cambio su contenido. Formulado de otra manera, si dentro de la información del día se ofrece nueva información sobre sucesos recientes relacionados con él, se podría afirmar que estas informaciones constituyen una noticia (VAN DIJK, 1990).

El propio día, su celebración y el espacio ocupado en los medios podría ser un ítem de la agenda periodística obligada profesionalmente a cubrir la celebración dándole el contenido propio del día, o, si se trata de recordar lo que sucedió tal día hace unos años, bien se podría pensar que se trata de una efeméride, dado que por efeméride se suele entender el acontecimiento notable que se recuerda en cualquier aniversario del mismo, o la conmemoración de dicho aniversario.

En resumen, se puede hablar de discurso periodístico, (VAN DiJk, 1990) para definir todo aquel texto, cualquiera que sea su naturaleza, contenido en el medio impreso. Como dice DADER (2000:24) "El que haya noticias sobre mujeres o presencia femenina en la selección informativa no significa necesariamente que la perspectiva o discurso que se utilice para narrar tales presencias haya modificado el dominante discurso andrógino...”.

${ }^{2}$ El año 2007, que fue elegido como Año Europeo de la Igualdad, fue un acicate para comenzar a observar y estudiar el tratamiento periodístico que los medios impresos dan al 8- $M$. 
El día elegido y el discurso elegido son una gran excepción. En modo alguno existe tal despliegue informativo con presencia femenina, se trata de una conmemoración muy especial.

\section{Objetivos}

El objetivo de este trabajo es poder dar respuesta a la pregunta: ¿Cuál es la posición de los medios impresos españoles (prensa diaria) frente al 8-M? Conocer el posicionamiento de la prensa española es prácticamente conocer también la opinión pública nacional, dada la estrecha relación entre la opinión pública y lo publicado. El objeto de estudio han sido por tanto los medios de comunicación escritos, o prensa diaria y más concretamente los periódicos aparecidos exclusivamente el 8 de marzo de 2007, que han sido alfabéticamente relacionados, y son los siguientes, por orden alfabético: ABC, El Mundo, El País y La Razón. Los espacios analizados son:

- Portada o Primera Página.

- Editorial y/o Opinión

- Sección o cuadernillo especial dedicado al 8 de Marzo 2007.

- Páginas de Sociedad

- Páginas de Trabajo y Economía

- Cartas al Director

- Anuncio Institucional

- Información General

- Viñetas

Se descartaron secciones como cuadernillos literarios porque entrañaba una gran dificultad dilucidar si el tema Mujer, era casual o voluntariamente relacionado con el 8-M. Por otra parte, el jueves es el día del Suplemento Literario en algunos diarios, con lo que los resultados del análisis estarían distorsionados de partida.

\section{Corpus de la investigación}

El corpus, claramente acotado y delimitado según los criterios expuestos anteriormente, se relaciona a continuación e igualmente aparecen en los cuadrosresumen correspondientes.

1. ABC - 8 de marzo, 2007

1.1. Día de la Mujer trabajadora

1.2. Juntas hacemos un mundo mejor

1.3. El permiso de paternidad será de cuatro semanas dentro de seis años.

1.4. La mujer autónoma y su "Torre de Babel"

1.5. La Reina con las mujeres africanas.

2. El Mundo - 8 de marzo, 2007

2.1. La utopía de la igualdad de derechos

2.2. Un velo islámico que no impide a los árabes participar en la sociedad.

2.3. "Las africanas no pueden permitirse el lujo de no ser fuertes". 
2.4. "El régimen iraní teme a las mujeres"

2.5. Trabajadora y discriminada

2.6. Juntas hacemos un mundo mejor

2.7. De la Vega anima a las africanas a avanzar a través de la política.

2.8. El Senado amplía el permiso de maternidad por parto prematuro.

3. El País - 8 de marzo, 2007

3.1. Pie de foto: "Hombre solo... y descolocado"

3.2. 500 mujeres en pie de igualdad.

3.3 El poder de las mujeres

3.4. El poder de las mujeres (continuación).

3.5. De la Vega: "La participación femenina en la política es la vía a una sociedad justa".

3.6. "No podemos invertir en nada".

3.7. Cifras de la situación de la mujer en África.

3.8. Cine de autora

3.9. Periodismo comprometido

3.10. Única juez del Supremo

3.11. La jefa de la universidad

3.12. El Senado aprueba la Ley de Igualdad en la víspera del día de la mujer.

3.13. Multas hasta de 90.000 euros por actitudes discriminatorias

3.14. Baja maternal

3.15. El $40 \%$ en el poder

3.16. Manos femeninas atizan el carbón.

3.17. Juntas hacemos un mundo mejor

3.18. Viñeta de Forges: Día de la Mujer.

4. La Razón - 8 de marzo, 2007

4.1. En femenino plural

4.2. La mujer en Afganistán

4.3. El futuro de África tiene nombre de mujer.

4.4. La Reina, contra la discriminación de la mujer en los países africanos.

4.5. El Senado adelanta a 2013 el mes de permiso paternal.

4.6. Juntas hacemos un mundo mejor.

4.7. El Día de la Mujer.

\section{Metodología}

Se realiza el estudio tanto cuantitativa como cualitativamente, analizando además temas como la agenda-setting, los efectos de la publicidad, o el humor en los medios de información impresos. Cuantitativamente se describe y cuantifica el espacio, sus características y la consiguiente comparación analítica de los mismos. Cualitativamente: se analiza el tratamiento lingüístico y periodístico de los 
diferentes artículos que componen el corpus, desde el giro lingüístico en ciencias sociales, lo que ha permite evaluar la sensibilidad del medio hacia el tema.

Conviene aclarar en este punto que la gran riqueza lingüística viene determinada por el autor del artículo, su sensibilidad, su modo de escribir, su adhesión a uno u otro medio, su ideología o su actitud personal o profesional ante el tema, y obviamente todo esto se puede escudriñar, analizar y valorar cuando existe un autor por medio, un periodista con su propia personalidad, o si se quiere, un artículo firmado. Lamentablemente, cuando el texto ha sido elaborado por una agencia, de la forma más neutra posible para su utilización en todos los medios de comunicación, esa riqueza diferenciadora no existe y no hay que olvidar que una parte nada desdeñable de los medios impresos se hace sobre la base de noticias de agencia lo que dificulta su valoración. No debe olvidarse que en periodismo, la forma es el fondo. Cabe deducir por tanto, que la actitud que un medio tiene hacia un tema la pone de manifiesto cuando jerarquiza, selecciona y trata el texto de una forma concreta: en una u otra página, con uno u otro espacio, con una o ninguna fotografía, con la creación de un cuadernillo monográfico, etc. En ocasiones ni siquiera se necesita recurrir a analizar la riqueza lingüística, sino que el mero análisis del tratamiento periodístico ofrece un posicionamiento claro. Sería deseable una estrecha correspondencia entre la forma y el fondo, pero no necesariamente obligatoria ni exacta. Mucho del lenguaje periodístico viene determinado por la utilización de los recursos, no sólo de redacción periodística, sino de tratamiento periodístico.

En lo relativo a la Agenda Setting (McComBs \& SHAw, 1972), con este concepto se alude al establecimiento de la agenda periodística, que frece un tipo de información que permite deducir las razones de la selección temática, en función también de las agendas políticas, de los temas emergentes y de las ideologías subyacentes. Según Robert Ezra PARK, uno de los miembros más relevantes de la Escuela de Chicago (1920-30), la jerarquización de los temas ofrecidos al público, estaba en manos del poder o de la agenda política. Por ello, la fijación de la agenda periodística (DADER, 1992), para cada medio de comunicación, ha permitido ver la convergencia o divergencia existente con las agendas políticas. En cuanto a las secuencias temporales de la producción de las diferentes agendas, ha resultado muy esclarecedor el hecho de poder establecer una convergencia de las agendas política y periodística. En la medida de su coincidencia, están más o menos alejados del tiempo óptimo de coincidencias de agendas (OES - Optimal effect span).

En lo concerniente a los Efectos publicitarios: La inserción de publicidad institucional es estudiada de una forma diferencial dado que también la naturaleza del texto es claramente distinta.

El Humor con carácter sintetizador. La capacidad de síntesis de las viñetas resulta muy clarificador a la hora de identificar cualquier tipo de discurso y la desdramatización a través de la ironía es un recurso utilizado con relativa frecuencia en los medios impresos. Así, mientras que el análisis cuantitativo arroja un tipo de información de base socioestadística, el cualitativo lo hace de forma sociolingüística. 
Las noticias, -no firmadas-, no se analizaron sociolingüísticamente dado que no aportan elemento diferenciador alguno. Sucede todo lo contrario con las fotografías, especialmente con la imagen de la Reina, que merece un epígrafe independiente.

La Reina. El hecho de que la Reina aparezca en un acto con fotografía puede convertir un acto privado o social en un acto público de marcado interés periodístico. La Reina, lejos de ser un ítem de interés sólo para los periódicos de tendencia monárquica, tiene interés para todos ellos. Por ello, la Reina, lejos de ser un ítem diferenciador en función de las tendencias ideológicas de los distintos medios de comunicación. Se torna en un elemento unificador, el centro de atención de todos ellos. Se produce un fenómeno similar con el papel de las agencias de información, convirtiéndose así en agentes unificadores.

\section{Aplicación metodológica}

\subsection{Parámetros cuantitativos}

Se estableció aquí una relación descriptiva de todos aquellos elementos externos y de presentación de la noticias, porque el tratamiento de los espacios, la inserción de las noticias en secciones concretas, la forma de diagramar una página, las líneas dedicadas al título, antetítulo o subtítulo, o el número de páginas o el tanto por ciento de ellas dedicadas a una noticia dejan ver la importancia que el periódico le confiere. Aspectos formales como su inclusión en una página par o impar tiene un efecto y una consideración distinta, de la misma forma que presentar o no una fotografía o un despliegue gráfico importante hablan de la relevancia del tema periodística y socialmente hablando.

El debate causa-efecto sobre si los medios de comunicación reflejan la sociedad, o es la sociedad la que toma sus patrones sociales de los medios de comunicación, aunque no pueda ser resuelto claramente, tampoco puede negarse la relación existente, por lo que la descripción detallada de los contenidos mediático ofrece una visión muy acertada de la importancia que cada medio confiere al tema. Por ello, se describen aspectos formales como el número de página en el que aparece (par o impar), nombre de la sección, parte superior o inferior de la página, el número de columnas que ocupa el texto, si está acompañado de una fotografía o cualquier otro tipo de ilustración gráfica.

Igualmente es muy significativo que un artículo esté firmado o no, con antetítulo y/o subtítulo o sin él, algún destacado, y el número de líneas que ocupa así como el número de columnas, o el porcentaje que la noticia representa en la página concreta o si está tipográficamente destacado. Todos estos aspectos formales, necesariamente presentes en el tratamiento periodístico de cualquier medio impreso, y no siempre fácilmente observables por el lector, son muy significativos para cualquier profesional de medios.

Se elaboró un cuadro-resumen que muestra las diferencias claramente y son fácilmente evaluables. 


\subsubsection{Cuadros resumen individualizados}

ABC: Cuadro resumen

\begin{tabular}{|c|c|c|c|c|c|c|c|}
\hline Título & Sección & Pág. & Foto/Dib. & Columnas & \%Pág & Color & Tipografía \\
\hline $\begin{array}{c}\text { Día de la Mujer } \\
\text { Trabajadora }\end{array}$ & $\begin{array}{c}\text { Cartas } \\
\text { Director }\end{array}$ & 8 & - & 2 & 20 & - & Recuadro \\
\hline $\begin{array}{c}\text { Juntas hacemos } \\
\text { un mundo mejor }\end{array}$ & Publicidad & 18 & Sí & 5 & 100 & Sí & Sí \\
\hline $\begin{array}{c}\text { El permiso de } \\
\text { paternidad será... }\end{array}$ & Sdad-España & 22 & - & 3 & 40 & - & Sí \\
\hline $\begin{array}{c}\text { La mujer } \\
\text { autónoma y su } \\
\text { torre... }\end{array}$ & Sdad-España & 24 & Sí & 5 & 100 & - & Sí \\
\hline $\begin{array}{c}\text { La Reina con las } \\
\text { mujeres de... }\end{array}$ & Sdad-España & 29 & Sí & 3 & 20 & Sí & - \\
\hline
\end{tabular}

\begin{tabular}{|l|l|}
\hline Total $\mathrm{n}^{\mathrm{o}}$ artículos & 5 \\
\hline Artículos en pág. impares & 1 \\
\hline Artículos en pág. impares & 4 \\
\hline Artículos $1^{\mathrm{a}}$ pág & 0 \\
\hline Suma $\mathrm{n}^{\circ}$ págs. (se excluye pág. publicidad) & 1,80 \\
\hline Publicidad & 1 \\
\hline Sección especial & 0 \\
\hline Fotos/infografía & 2 \\
\hline
\end{tabular}

El Mundo: Cuadro resumen

\begin{tabular}{|c|c|c|c|c|c|c|c|}
\hline Título & Sección & Pág. & Foto/Dib. & Columnas & \%Pág & Color & Tipografía \\
\hline $\begin{array}{c}\text { La utopía de la } \\
\text { igualdad de ... }\end{array}$ & $8-\mathrm{M}$ & 30 & Sí & 5 & 70 & - & Negrita \\
\hline $\begin{array}{c}\text { Un velo islámico } \\
\text { que no impide... }\end{array}$ & $8-\mathrm{M}$ & 30 & - & 3 & 30 & - & Negrita \\
\hline $\begin{array}{c}\text { Las africanas no } \\
\text { pueden ... }\end{array}$ & $8-\mathrm{M}$ & 31 & Sí & 5 & 55 & - & destacado \\
\hline $\begin{array}{c}\text { El régimen iraní } \\
\text { teme a las... }\end{array}$ & $8-\mathrm{M}$ & 31 & Sí & 5 & 45 & - & destacado \\
\hline $\begin{array}{c}\text { Trabajadora y } \\
\text { discriminada }\end{array}$ & Economía & 41 & Sí & 4 & 60 & - & Negritas \\
\hline $\begin{array}{c}\text { Juntas hacemos } \\
\text { un mundo... }\end{array}$ & Publicidad & 29 & Sí & 5 & 100 & Sí & Sí \\
\hline $\begin{array}{c}\text { De la Vega anima } \\
\text { a las africanas... }\end{array}$ & España & 22 & Sí & 3 & 55 & - & - \\
\hline $\begin{array}{c}\text { El Senado amplía } \\
\text { el permiso... }\end{array}$ & España & 22 & - & 1 & 15 & - & - \\
\hline
\end{tabular}

\begin{tabular}{|l|l|}
\hline Total $\mathrm{n}^{\circ}$ artículos & 8 \\
\hline Artículos en pág. impares & 4 \\
\hline Artículos en pág. impares & 4 \\
\hline
\end{tabular}




\begin{tabular}{|l|l|}
\hline Artículos $1^{\text {a }}$ pág & 0 \\
\hline Suma $\mathrm{n}^{\circ}$ págs. (se excluye pág. publicidad) & 3,30 \\
\hline Publicidad & 1 \\
\hline Sección especial & 1 \\
\hline Fotos/infografía & 5 \\
\hline
\end{tabular}

El País: Cuadro resumen

\begin{tabular}{|c|c|c|c|c|c|c|c|}
\hline Título & Sección & Pág & Foto/Dib. & Columnas & \%Pág & Color & Tipografía \\
\hline $\begin{array}{c}\text { Hombre solo... y } \\
\text { descolocado }\end{array}$ & Primera & 1 & Sí & 4 & 35 & Sí & - \\
\hline $\begin{array}{l}500 \text { mujeres en } \\
\text { pie de igu... }\end{array}$ & Primera & 1 & No & 2 & 10 & - & - \\
\hline $\begin{array}{c}\text { El poder de las } \\
\text { mujeres }\end{array}$ & Opinión & 15 & No & 5 & 55 & - & - \\
\hline $\begin{array}{l}\text { El poder de las } \\
\text { mujeres (cont.). }\end{array}$ & Opinión & 16 & No & 5 & 10 & - & - \\
\hline $\begin{array}{l}\text { De la Vega: La } \\
\text { participación... }\end{array}$ & $\begin{array}{l}\text { Sdad/Lucha } \\
\text { Igualdad }\end{array}$ & 36 & Sí & 5 & 65 & Sí & - \\
\hline $\begin{array}{c}\text { No podemos } \\
\text { invertir en nada }\end{array}$ & $\begin{array}{l}\text { Sdad/Lucha } \\
\text { Igualdad }\end{array}$ & 36 & Sí & 5 & 20 & Sí & - \\
\hline $\begin{array}{l}\text { Cifras de la } \\
\text { situación de la } \\
\text { mujer }\end{array}$ & $\begin{array}{l}\text { Sdad/Lucha } \\
\text { Igualdad }\end{array}$ & 36 & No & 1 & 15 & - & Negrita \\
\hline Cine de autora & $\begin{array}{l}\text { Sdad/Lucha } \\
\text { Igualdad }\end{array}$ & 37 & Sí & 5 & 25 & No & - \\
\hline $\begin{array}{c}\text { Periodismo } \\
\text { comprometido }\end{array}$ & $\begin{array}{l}\text { Sdad/Lucha } \\
\text { Igualdad. }\end{array}$ & 37 & Sí & 5 & 25 & No & - \\
\hline $\begin{array}{l}\text { Única juez del } \\
\text { Supremo }\end{array}$ & $\begin{array}{l}\text { Sdad/Lucha } \\
\text { Igualdad }\end{array}$ & 37 & Sí & 5 & 25 & No & - \\
\hline $\begin{array}{l}\text { La Jefe de la } \\
\text { Universidad }\end{array}$ & $\begin{array}{l}\text { Sdad/Lucha } \\
\text { Igualdad }\end{array}$ & 37 & Sí & 5 & 25 & No & - \\
\hline $\begin{array}{c}\text { El Senado } \\
\text { aprueba la Ley de } \\
\text { I. }\end{array}$ & $\begin{array}{l}\text { Sdad/Lucha } \\
\text { Igualdad. }\end{array}$ & 39 & Sí & 2 & 40 & Sí & - \\
\hline $\begin{array}{l}\text { Multas hasta de } \\
90.000 \text { euros.. }\end{array}$ & $\begin{array}{l}\text { Sdad/Lucha } \\
\text { Igualdad }\end{array}$ & 39 & No & 2 & 20 & No & - \\
\hline Baja maternal & $\begin{array}{l}\text { Sdad/Lucha } \\
\text { Igualdad }\end{array}$ & 39 & No & 1,5 & 15 & No & - \\
\hline $\begin{array}{l}\text { El } 40 \% \text { en el } \\
\text { poder }\end{array}$ & $\begin{array}{l}\text { Sdad/Lucha } \\
\text { Igualdad }\end{array}$ & 39 & No & 1,5 & 15 & No & - \\
\hline $\begin{array}{c}\text { Manos femeninas } \\
\text { atizan ... }\end{array}$ & $\begin{array}{l}\text { Sdad/Lucha } \\
\text { Igualdad }\end{array}$ & 40 & Sí & 5 & 80 & No & Destacado \\
\hline $\begin{array}{c}\text { Juntas hacemos } \\
\text { un mundo... }\end{array}$ & Publicidad & 29 & Sí & 5 & 100 & Sí & $\begin{array}{l}\text { Sí } \\
\end{array}$ \\
\hline Viñeta de Forges & Opinión & 14 & Sí & 3 & 15 & No & Sí \\
\hline
\end{tabular}




\begin{tabular}{|l|c|}
\hline Total $\mathrm{n}^{\circ}$ artículos & 18 \\
\hline Artículos en pág. impares & 12 \\
\hline Artículos en pág. impares & 6 \\
\hline Artículos $1^{\text {a }}$ pág & 2 \\
\hline Suma $\mathrm{n}^{\circ}$ págs. (se excluye pág. publicidad) & 4,95 \\
\hline Publicidad & 1 \\
\hline Sección especial & 1 \\
\hline Fotos/infografía & 10 \\
\hline
\end{tabular}

La Razón: Cuadro resumen

\begin{tabular}{|c|c|c|c|c|c|c|c|}
\hline Título & Sección & Pág. & Foto/Dib. & Columnas & \%Pág & Color & Tipografía \\
\hline $\begin{array}{c}\text { En femenino } \\
\text { plural }\end{array}$ & Opinión & 6 & No & 4 & 15 & - & - \\
\hline $\begin{array}{c}\text { La Mujer en } \\
\text { Afganistán }\end{array}$ & Tribuna & 26 & No & 5 & 40 & - & - \\
\hline $\begin{array}{c}\text { El futuro de } \\
\text { Africa tiene } \\
\text { nombre }\end{array}$ & $\begin{array}{c}\text { Punto de } \\
\text { Mira }\end{array}$ & 3 & Sí & 5 & 100 & Sí & - \\
\hline $\begin{array}{c}\text { La Reina, contra } \\
\text { la discrimina... }\end{array}$ & $\begin{array}{c}\text { Sdad/As. } \\
\text { Soc. }\end{array}$ & 30 & Sí & 3 & 40 & - & - \\
\hline $\begin{array}{c}\text { El Senado } \\
\text { adelanta a 2013... }\end{array}$ & $\begin{array}{c}\text { Sdad/As. } \\
\text { Soc. }\end{array}$ & 30 & No & 2 & 35 & - & - \\
\hline $\begin{array}{c}\text { Juntas hacemos } \\
\text { un mundo... }\end{array}$ & \begin{tabular}{c} 
Publicidad \\
\hline
\end{tabular} & 35 & Sí & 5 & 100 & Sí & Sí \\
\hline
\end{tabular}

\begin{tabular}{|l|c|}
\hline Total $\mathrm{n}^{\circ}$ artículos & 7 \\
\hline Artículos en pág. impares & 2 \\
\hline Artículos en pág. impares & 5 \\
\hline Artículos $1^{\text {a }}$ pág & 0 \\
\hline Suma $\mathrm{n}^{\circ}$ págs. (se excluye pág. publicidad) & 2,40 \\
\hline Publicidad & 1 \\
\hline Sección especial & 0 \\
\hline Fotos/infografía & 2 \\
\hline
\end{tabular}

\subsection{Parámetros cualitativos}

Analizar los parámetros cualitativos desde lo que se conoce en Sociología como el giro lingüístico, obligó a examinar minuciosamente todos los elementos de sentido, desde la elección del vocabulario hasta los signos cargados de significado, lo que unido a los parámetros cuantitativos permitió extraer conclusiones definitivas y alcanzar una valoración final. Cada artículo fue analizado como una unidad de análisis, desde tres grandes bloques lingüísticos, a saber: Lenguaje periodístico: atendiendo a que éste, por su naturaleza (la celeridad marca el lenguaje), a lo que se suma la regla de oro: brevedad, concisión y claridad, no facilita una gran riqueza lingüística. En cambio sí permite analizar su actitud y su tono por su propia redacción periodística junto con la distribución de los espacios; Lenguaje 
publicitario: que atiende a la publicidad institucional y no comercial, donde existen una serie de parámetros que son válidos para ambos lenguajes; y Lenguaje humorístico: su iconicidad permite una gran diversidad de lecturas. La desdramatización, la caricaturización y la ironía están habitualmente presentes en cualquier viñeta humorística. La unión de estos recursos ofrece una gran riqueza analítica, que sin duda alguna suministra una valiosa información.

El análisis de la publicidad institucional tiene un enfoque y un tratamiento distintos de la publicidad comercial dirigida a la venta del producto publicitado. Se trata aquí por tanto la publicidad con un enfoque lineal (LEóN, 1996) que recoge tres aspectos bien distintos de la venta, a saber: un aprendizaje (atendiendo a los efectos cognitivos), una actitud (atendiendo a los efectos de convencimiento y afecto) y una acción (atendiendo a los efectos de comportamiento). En el caso estudiado, al ser publicidad -institucional-, no comercial, los efectos son lineales, pero atienden a los efectos cognitivos, actitudinales y comportamentales.

El análisis humorístico en viñetas periodísticas ofrece distintas posibilidades. De una parte, participa tanto del género de la noticia-información como del de la críticaestética, ya que su discurso cubre prácticamente todos los elementos discursivos periodísticos. En una sola imagen, o en una sola viñeta, su autor puede ser mucho más expresivo que un periodista en toda una página del periódico. De otra, el lenguaje icónico permite infinidad de lecturas, casi tantas como lectores, sin necesidad de entrar en un lenguaje escrito que puede, ocasionalmente, ser bastante más comprometido. Dado que los recursos del lenguaje humorístico son infinitos, de entre ellos sobresalen éstos:

- Desdramatización irónica

- Caricaturización de los personajes

- Ausencia de censura o autocensura

- Utilización de la ironía.

\section{Discusión y conclusiones}

\subsection{Parámetros cuantitativos}

Dada la importancia que tienen los datos numéricos resultado de la medición de los parámetros cuantitativos, el cuadro resumen final tiene la virtualidad de sintetizar de una mirada los datos que, por sí solos, resultan absolutamente significativos e incuestionables.

Cuadro resumen final

\begin{tabular}{|c|c|c|c|c|}
\hline & $\boldsymbol{A B C}$ & El Mundo & El País & La Razón \\
\hline Total n $^{\mathbf{0}}$ Artículos & 5 & 8 & 18 & 7 \\
\hline Art. en pág. impares & 1 & 4 & 12 & 2 \\
\hline Art. en pág. pares & 4 & 4 & 6 & 5 \\
\hline Art. primera página & 0 & 0 & 2 & 0 \\
\hline Suma n ${ }^{\mathbf{0}}$ de páginas & 1,80 & 3,30 & 4,95 & 2,40 \\
\hline Publicidad $^{-1}$ & 1 & 1 & 1 \\
\hline Sección especial & 0 & 1 & 1 & 0 \\
\hline Fotos/Dib./Gráficos & 2 & 5 & 10 & 2 \\
\hline
\end{tabular}




\section{Éstas son algunas de las conclusiones:}

1. El primer y el más importante termómetro de un periódico es su PRIMERA PÁGINA. No siempre con facilidad, los Consejos de Redacción deciden los temas que irán en portada. Necesariamente ha de existir una jerarquización temática aprobada y ejecutada. La primera página contiene los temas más importantes y las referencias o sumarios de los temas que serán tratados en el interior. Nunca iría la noticia más importante en una página interior, a una columna y en tres líneas, lo que inequívocamente constituye la primera jerarquización. El cuadro-resumen-final lo muestra. El País es el periódico que más referencias hace al tema en su portada (2). El resto ha priorizado sus temas sin incluir El 8-M.

2. Siendo el segundo indicador el espacio absoluto dedicado (en número de artículos), El País vuelve a ser el diario que más artículos dedica al tema en números absolutos (18), seguido por El Mundo (8), La Razón (7) y por último $A B C$ (5).

3. El tercer indicador es el número de páginas que han dedicado al tratamiento del tema. Este dato proviene de la suma de los espacios porcentuales dedicados en cada artículo por página. La suma de los porcentajes arroja el número de páginas totales provenientes de la suma de los artículos de las secciones generales o de secciones especialmente creadas para el 8-M. El País es el diario que más páginas ha dedicado al tratamiento del tema $(4,95)$ prácticamente 5 páginas completas. Le sigue El Mundo (3,30), El Mundo $(2,40)$ y en último lugar $A B C(1,80)$, sin haber tenido en cuenta que el formato del diario $A B C$ el más pequeño de los cuatro. No se tuvo en cuenta la página completa dedicada a la publicidad institucional.

4. El cuarto indicador fueron las imágenes. En la cultura de la imagen actual, se aprecia una estrecha relación con el espacio ocupado o el número de artículos dedicados al tema. Nuevamente, el periódico que se destacó fue El País con 10 fotografías/dibujos/gráficos, seguido por El Mundo con 5, y La Razón y ABC con 2. El País fue el único periódico que le dedicó una viñeta humorística (Forges) al tema.

5. Un parámetro importante, que los publicistas y publicitarios suelen tener muy en cuenta es el tipo de página, si es par o impar. Está demostrado que las páginas impares tienen un mayor número de lectores, con un tiempo de lectura más largo, razón ésta por la que la publicidad es más cara en páginas impares que en pares. Por ello, además de haber contemplado el número de páginas y de imágenes, se observó también la proporción de páginas impares frente a las pares que los medios dedicaron al tema. De nuevo, El País utilizó 18 páginas totales, 12 de ellas eran impares, que representan 18/12. Seguiría El Mundo 8/4, La Razón 7/2, y por último $A B C 5 / 1$.

6. Otro indicador es la aparición de una sección monográfica. ABC y La Razón no introdujeron sección monográfica alguna. Nuevamente, El País, lo hizo, dándole un nombre especial a la sección: "La Lucha por la Igualdad”, que a su vez tenía una estrecha relación con el Acto Público que se organizaba para la conmemoración de tal evento y con la aprobación, el día anterior, de la Ley de Igualdad. Se produce un OES (Optimal Effect Span), es decir de un tiempo óptimo de coincidencia de agendas. 
7. Se insertó publicidad institucional en todos ellos. Hecho que informa de que el tema es no sólo una parte importante de la agenda presupuestaria interna, sino también de la agenda política que el Ministerio de Trabajo y Asuntos Sociales ${ }^{3}$ (en adelante MTAS) tiene establecido para este tema. No tendría una partida presupuestaria, de no ser así, lo que produce una convergencia de las agendas periodísticas con las políticas, lo cual magnifica sus efectos sobre la opinión pública.

8. Otro medidor es el color. No es lo mismo que las fotografías sean insertadas en blanco y negro o en color. Las fotografías ordinarias, de temas comunes, van, por razones de coste en blanco y negro $(\mathrm{B} / \mathrm{N})$. El color se destina a temas destacados. Cabe destacar la incorporación de algunos medios al color para las fotografías de este día. Así pues $A B C$ de 3 fotografías le dedica 1 al color, es decir 3/1 (publicidad excluida); El Mundo 5/0 (publicidad excluida); El País 10/4 (publicidad excluida); y La Razón 2/1 (publicidad excluida).

\subsection{Parámetros cualitativos}

Bajo este epígrafe se analizaron todos aquellos aspectos, que no poseen un carácter cuantitativo y por ende, no pueden ser medidos. Estos parámetros permitieron responder las preguntas formuladas al comienzo de este trabajo, que se revisan a continuación.

\subsubsection{El titular}

Mención especial merecen los titulares. En redacción periodística existe un punto clave y central en la aproximación a una noticia: el lector leerá o no la noticia en función de su titular. Del título de una noticia se pueden lograr infinidad de efectos, tales como:

- Llamar la atención del lector.

- Presentar un título representativo de la noticia, aunque sólo sea de un ángulo.

- Manifestar la actitud (positiva de aprobación o negativa de rechazo) hacia el tema del que se esta informando.

- Buscar connotaciones o asociaciones cargadas de sentido en otro tipo de lenguaje distinto del periodístico, desde literarias a históricas, bélicas a deportivas.

- Sintetizar, incluyendo todos los ángulos (con la ayuda del antetítulo y subtítulo habitualmente).

- Generar una sensación de equilibrio o de armonía.

- Buscar un efecto de debate o discusión abierta.

- Crear complicidades o adhesiones.

- Generar efectos perversos, odiosos o adversos.

${ }^{3}$ El Ministerio de Trabajo y Asuntos Sociales, en la parte relativa a las cuestiones de género, fue asumido por el Ministerio de Igualdad, según R.D. 1135/2008 de 4 de julio de 2008. No obstante, y a pesar de que este trabajo vea la luz con posterioridad a esa fecha, se respeta la denominación que tenía en el momento de la aparición de los artículos analizados. 
- Producir ambigüedad, confusión, incertidumbre.

- Muchos otros efectos que pueden aparecer circunstancialmente.

Es, precisamente, por todas estas posibilidades periodísticas a la hora de titular una noticia por los que hubo que detenerse de forma muy especial en los títulos. Ellos, como las viñetas humorísticas tienen una gran capacidad sintetizadora y muestran, a veces involuntariamente, mucho más de la intención o de la actitud de su autor de la que éste imaginar jamás.

\subsubsection{Agenda setting}

Tras haber descrito la tematización o la canalización periodística, lo primero que hay que definir es el tipo de tema que es: un item emergente, de temporalidad anual y abierto, o una noticia común. Se trata de un tema crónico (cada 8 de marzo), pero no gastado, y de temporalidad anual (cada año), y abierto porque permite la entrada y la incorporación de temas nuevos emergentes convergentes con la efeméride. El análisis de la agenda-setting informa de la posición del medio con relación a su jerarquización. El establecimiento de los temas es cada vez más importante en la fijación de cualquier agenda, y muy especialmente en las agendas periodísticas o mediáticas. Existen algunos hechos o serie de coincidencias a valorar, -casuales o programadas- donde se dan una serie de actos y eventos políticos y periodísticos coincidiendo con la celebración del 8- $M$, que se muestran a continuación.

\subsubsection{Coincidencias y convergencias de agendas}

Aparece una clara coincidencia y/o convergencia de agendas. La agenda política incluía para este tema la aprobación de la ley de Igualdad precisamente la víspera del 8-M, y la celebración del evento político-social más importante del día, coincide con el interés de los medios de comunicación impresos en cubrir la efeméride de forma extraordinaria el 8-M y la presencia de la Reina. La agenda política tiene una perfecta cobertura en los periódicos porque el tema es parte de su agenda periodística. No sólo se trata de una coincidencia temática sino también temporal. Se presenta un Tiempo Óptimo de coincidencia de agendas ("Optimal Effect Span”), ejecutado de esta forma:

- Día 7 de Marzo: Aprobación de la Ley de Igualdad. II Encuentro Internacional de Mujeres España - África.

- Día 8 de Marzo: Publicación de la aprobación de la Ley de Igualdad. Celebración del 8-M

Se trata de una coincidencia feliz, no de una conmemoración estricta, de recuerdo, de efeméride. El hecho de la convergencia de las agendas políticas y periodísticas confiere a la jornada una naturaleza difícil de definir a priori, pero muy rica y llena de contenido, lo que produce tiempos óptimos de coincidencias de agendas. La situación de homogeneidad no es la misma para todos los medios de comunicación impresos analizados.

Como se apuntó en la evaluación los parámetros cuantitativos en las primeras conclusiones, El País fue el periódico que mostró una mayor coincidencia con la 
agenda política, mientras que $A B C$ fue el que menor convergencia tuvo. La agenda temática de las instituciones, en este caso el MTAS, la Secretaría General de Políticas de Igualdad, junto con el Instituto de la Mujer (en adelante IM), o lo que se conoce en los estudios de medios como "policy agenda" ejercen una gran influencia sobre la selección periodística del tema.

La agenda política tiene una forma directa de manifestar sus ítems a través de la publicidad. El hecho de que un Ministerio tenga una partida presupuestaria para Publicidad, significa que va a cubrir el evento político de forma inequívoca. Aunque no se produjera ningún acontecimiento noticiable para la agenda periodística, la publicidad estaría presente en los medios y esa inserción de publicidad pagada tiene una repercusión directa también en los contenidos de los medios impresos: aunque sólo sea recordatorio del evento, de ahí que la publicidad no pueda desdeñarse ni ignorarse, dado que cumple varios fines, los llamados efectos publicitarios.

Cabe preguntarse si es casual, o no, que la agenda periodística de El País coincida con la agenda política del Gobierno, y no suceda así con el $A B C$ ahora que gobierna el PSOE.

\subsubsection{Efectos publicitarios}

El anuncio institucional insertado es igual para todos lo que permite analizar los tres periódicos simultáneamente. El lenguaje publicitario que se contempla es el creado por el MTAS. No es un reflejo de las líneas editoriales de los periódicos analizados: ABC, El Mundo, El País, y La Razón. La única diferencia entre ellos se halla en el tipo de página que ha sido insertada: par o impar.

El primer valor de este anuncio institucional del IM es la virtualidad de convertirse en un elemento unificador, es decir, tienen una single source, en el plano publicitario, los cuatro medios presentan un mismo anuncio, le dan al lector una sensación de unificación, lo que produce un mayor efecto en el ciudadano que si cada uno presentara su publicidad propia y diferenciadora de los otros periódicos. Mientras que en la publicidad comercial el lenguaje es lineal, es decir el proceso de conocimiento, de la actitud y del acto final, va dirigido a conseguir el acto de consumo, en la publicidad institucional no cabe pensar en venta ni en consumo pero sí, mutatis mutandi, en los mismos efectos que consigue la publicidad comercial. Es decir, el lector medio de prensa diaria sabrá que se está celebrando, conmemorando o reivindicando una jornada que tiene interés para el MTAS, con lo que, el día deja de ser un día para las sufragistas, para convertirse en una jornada importante de interés para el Gobierno y que recogen todos los medios de comunicación cualquiera que sea su color ideológico, lo que hará que algunos lectores cambien su actitud hacia el 8-M, siendo otro su mentalidad, aunque en la práctica no se produzcan grandes cambios inmediatos. El objetivo final es conseguir un aumento en la sensibilidad del ciudadano hacia el tema del 8-M.

En el análisis de los elementos publicitarios, se puede concluir que:

1. Persigue llegar a todos los ciudadanos, de ahí que haya elegido un lenguaje publicitario que lleva implícitas las características del periodismo: el mensaje claro, conciso y directo. 
2. En segunda lectura, se puede establecer una vinculación que une al Gobierno (MTAS) con la Monarquía (Reina) y todas las ciudadanas de África y España. La asociación viene condicionada por la elección de un rostro negro, cuando se celebra el II Encuentro Internacional de Mujeres España-África. La asociación es automática e inevitable.

3. Es polivalente. La cara de la joven negra, tanto podría ser el de una universitaria, como el de una joven rural africana, como el de una modelo o una mujer maltratada. Tiene mucha fuerza precisamente porque la falta de definición hace que el lector pueda hacer su lectura personalizada.

4. Resulta muy permanente. Al tener un diseño en diagonal, muy sencillo, es de fácil recuerdo, prácticamente imposible olvidarlo, por lo que permanece en la retina y en la memora como un elemento perdurable.

5. Es innovador y rompedor de esquemas. Mientras que normalmente a lo africano se le atribuye mucho color, mucha alegría, mucho brillo, el anuncio ha elegido unos colores realmente sobrios y austeros que rompen los esquemas preestablecidos.

\subsubsection{Efectos humorísticos}

Una de las innegables características del lenguaje humorístico, y más concretamente de las viñetas es la capacidad de síntesis. A veces, un humorista, de la talla de Forges, puede decir en una de sus viñetas lo mismo que necesitaría un filósofo en una monografía. La grandeza de su capacidad de síntesis es que no pierde por ello riqueza expresiva. Dicho de otra forma, mientras que en un lenguaje escrito sintético: un telegrama, por ejemplo, tiene capacidad de síntesis, pierde en cambio toda su riqueza expresiva, que en las viñetas se mantiene íntegramente, cuando no es reforzada por la expresividad de sus personajes. Forges utiliza los recursos de desdramatización, de caricaturización y de la ironía magistralmente. Independientemente de las viñetas, se ha podido percibir cierto sentido del humor en artículos muy serios, como la portada de EL PAÍS, cuya foto central a color se titulaba: "solo... y descolocado".

Habida cuenta de que hay una gran tendencia a dramatizar las noticias, el lenguaje humorístico o la fina ironía son recursos muy apreciables a la hora de eliminar el hierro existente en la mayor parte de las noticias, sin que por ello pierda importancia la noticia.

\subsection{Análisis cualitativo y conclusiones por medios}

El resultado del análisis cualitativo, medio a medio, permitió concluir lo siguiente:

6.3.1. ABC: Este medio mostró un bajísimo grado de implicación con el tema del 8M, lo que se plasmó de dos formas: la primera: es el que menor espacio le dedica y consecuentemente tiene poco interés para sus lectores. El primer ejemplo aparece con la Carta al Director analizada. En ella se muestra una actitud reivindicativa, muy poco documentada, que informa de la ausencia de implicación de la autora con el tema, en lógica armonía con el medio. Aquí teoría y praxis reflejan la afinidad entre 
el medio y sus lectores, ideológicamente hablando, sobre todo. Es muy curioso el hecho de que sus títulos no tengan un claro sentido positivo. Por ejemplo: "El permiso de paternidad será de cuatro semanas dentro de seis años” se centra precisamente en un logro que aparece muy aplazado en el tiempo (6 años), mientras que no se destacan en el título los aspectos positivos que entran en vigor después de la vacación de la ley, es decir, 20 días después de su publicación en el BOE. Paradójicamente son unos cuantos aspectos positivos los que recoge la Ley de Igualdad. El artículo que procede de una colaboración externa, es bastante ajustado a la realidad, y podría haber sido publicado en cualquier otro periódico. La razón es que la autora no es periodista, ni de plantilla, sino que es una mujer autónoma. Su último artículo hace referencia a la imagen de la Reina, donde se destaca más su presencia que los propios contenidos del Encuentro Internacional.

6.3.2. EL MUNDO. Después de El País es el periódico más comprometido con el tema del 8-M. Sus artículos son de elaboración propia, firmados y presentan los diferentes ítems con un enfoque particular. Así, el primer artículo firmado por dos mujeres ofrece dos cuadros elaborados a partir de un informe del Fondo Económico Mundial y más concretamente el Informe de las Distancias por Género, 2008, En un cuadro describe la situación de la mujer en el mundo y establece una comparación con la situación de la mujer en Suecia en el segundo. A pesar de las cifras que reflejan datos estadísticos, las autoras se plantean la dificultad de conciliar la vida familiar con la profesional, todavía sin resolver de una forma real, y pone a los países nórdicos como referencia. Un buen trabajo periodístico, serio, documentado y ponderado.

El segundo título transporta al mundo islámico. Plantea en tono serio pero relajado que el velo no impide a las mujeres musulmanas participar en la lucha por la igualdad, pero sí se lo dificulta.

El tercero, firmado por Fátima Ruiz, transporta al lector a África y ofrece el testimonio de la Presidenta del Parlamento de la Unión Africana: Gertrude Mongella. No podría haber elegido un testimonio mejor: ella es el símbolo de la liberación de la mujer africana. Paradójicamente, Liberia ya tiene la primera presidenta, lo que no han conseguido muchos países europeos.

El cuarto, para justificar el contenido del segundo artículo, incorpora el testimonio de una mujer iraní, la profesora Azar Nafisi, autora de Leer Lolita en Teherán, todo un ejemplo de mujer comprometida incluso para las occidentales, más aún para la iraníes. Deja muy claras algunas de sus reivindicaciones: "que el velo sea una opción personal, cambiar la ley que regula la custodia de los hijos que, tras la muerte del marido son arrebatados a sus madres y confiados a otros hombres de la familia”.

El quinto artículo vuelve a ser un artículo de elaboración propia y de máxima implicación con el tema del 8-M que presenta la situación de la mujer discriminada en España. Han utilizado los datos de la Fundación ADECCO que son tan demoledores como fiables: el 43 por ciento. De los afiliados a la Seguridad Social son mujeres y siguen cobrando menos, y soportando las mayores tasas de temporalidad, sin acceso a los puestos de dirección. 
El sexto artículo introduce el II Encuentro Internacional de Mujeres EspañaÁfrica, el más importante de los organizados para conmemorar el día. Lo hace con las palabras de nuestra Vicepresidenta de Gobierno, Teresa Fernández de la Vega, quien pronuncia dos frases que van más allá del deseo: romper los espacios de discriminación y construir espacios de libertad. Las dos frases están cargadas de compromiso y de fuerza, de implicación y de complicidad con las mujeres africanas. Corona su discurso con otra: "la mujer posee los mejores activos para el desarrollo de la paz $^{4}$ y la prosperidad en todas las sociedades”, utilizando para ello la política.

El séptimo, presenta una parte de la Ley de Igualdad, también presente en los periódicos previamente analizados, pero destacando los aspectos positivos. $\mathrm{La}$ Reina vuelve a ser el centro de atención de las cámaras.

6.3.3. EL PAÍ́S. Es muy encomiable que su primer artículo presente un pie-de-fototitular tan divertido, dado lo infrecuente de ver tal concentración de mujeres y tal escasez de hombres, siendo mucho más habitual lo contrario. El título juega a mostrar lo irreal, lo infrecuente, lo chocante, o quizá un futuro próximo... De cualquier forma, la gran fotografía a color es el elemento más destacable en esta primera plana. Un lenguaje icónico cargado de sentido y de significados, punto central de la jornada 8-M.

El segundo artículo que aparece en primera página tiene un título que permite hacer algunos comentarios. La expresión de su título: "500 Mujeres en pie de igualdad” remite rápidamente a otra más bélica, pero con la misma estructura: 500 Mujeres en pie de guerra. La asociación es automática e incluso el sentido no es muy distinto, a pesar de que se haya utilizado un término más democrático y menos bélico. Esto redondea y cierra el discurso establecido por la Vicepresidenta de gobierno, al hablar de los activos que posee la mujer para alcanzar la paz y el progreso. La inclusión del número (500) en el titular tampoco resulta estéril. Se trata de mostrar fuerza, y 500 es un número muy importante, especialmente cuando se trata de mujeres luchadoras y representantes de los distintos países del continente africano y representantes españolas en sus distintas áreas: 300/200.

El tercer artículo es de opinión, firmado por Daniel Innerarity. La frase "El poder de las mujeres" lleva casi indefectiblemente a otra asociada a términos bélicos: El poder de las armas, con lo que se produce un interesante juego de palabras, asociaciones y significados. El autor sentencia que el mundo político sigue siendo cosa de hombres, y cuando una mujer accede a él, las exigencias son mayores que para los hombres. Hace referencia al caso actual más llamativo el de Segolene Royal. Formada en la ENA como la mayor parte de los líderes franceses, y con una gran experiencia política, habiendo ocupado carteras ministeriales, siempre se le sigue viendo y juzgando como a una mujer. El ventajismo masculino es

\footnotetext{
${ }^{4}$ Personalmente no puedo estar más de acuerdo con ella. Prueba de ello es mi ensayo titulado Paz: femenino, singular.¿Una beatería feminista o una aportación femenina?, que mereció el V Premio de la Cátedra Leonor de Guzmán, publicado por la Universidad de Córdoba, 2005 y que precisamente describe las características y las diferencias biológicas y psicológicas que la mujer posee para la contribución al proceso de paz.
} 
omnipresente en el mundo político internacional. Paradójicamente, las puertas que pueden abrir la carrera del éxito a una mujer suelen ser las que se la cierran después.

El cuarto artículo, continuación del tercero, que aparece en la página siguiente, concluye con la idea de que el poder de las mujeres no reside en aquel que complementa o corrige el poder de los hombres, sino en el que pueda sustituirlo. El miedo ancestral y tribal de los hombres hacia el poder de las mujeres vuelve a aparecer, disfrazado de democracia, cambiado en su forma, pero igual de destructivo y de aniquilador.

El quinto artículo, también firmado, De la Vega vuelve a recalcar lo que ya apuntaba en la primera página y cuyo contenido está resumido en el título: "La participación femenina en la política es la vía a una sociedad justa”. Va avanzando en la configuración de la participación política de la mujer y para ello apunta tres vías claves: la educación, sanidad y la economía. Áreas éstas que, quizá salvando un poco la economía, siempre han sido patrimonio de la mujer, desde las tribus más primitivas hasta las sociedades más avanzadas, si se tienen en cuenta los estereotipos de maestras y enfermeras. El lenguaje icónico de la fotografía vuelve a destacar lo diverso y colorista del II Encuentro Internacional que contrasta con la seriedad del traje oscuro del Ministro Moratinos, una vez más descolocado. Destacable, en lenguaje simbólico, la importancia y la pertinencia del color elegido por la Reina para un acto de esta naturaleza: lila.

En el sexto artículo, firmado, la autora extrae su titular de las palabras de la Premio Nobel de la Paz 2004, Wangari Maathai. El nivel de los testimonios elegidos no es precisamente desdeñable. Ella propone las tres erres, consistentes en reciclar, reducir y reutilizar, porque la mujer africana no puede invertir en nada. Se trata de la nueva economía de subsistencia. Mientras que los países del primer mundo navegan en la economía del consumo y de la opulencia, ella propone las tres erres, lo que enlaza directamente con una economía sostenible y con la rehabilitación de los bosques que ella había comenzado, con éxito, en su país natal. Denuncia dos hechos. El primero es que se extrae más agua de la que llega y el segundo es que África se ha convertido en el exportador de materias primas que luego el continente ha de comprar como manufacturadas. Muy oportuna también resulta su indumentaria, representando al continente y llena de vida y de color, y de esperanza (verde).

El séptimo artículo, como su título indica, se trata de "Cifras de la situación de la mujer en África”. Esta columna ofrece un glosario de los términos más importantes para el desarrollo de la mujer africana. El último de ellos: alfabetización, habla de un 54 por ciento de las mujeres alfabetizadas. Hoy nos puede parecer aterrador, pero España hasta la Guerra Civil no tenía una tasa mejor. Ellas van avanzando muy rápido. Esa es la ventaja de subirse a un carro que ya lleva mucho camino recorrido, y es que llega enseguida a destino.

El octavo artículo es el primero firmado de una serie de cuatro semblanzas femeninas: cuatro mujeres destacables africanas. Este artículo, titulado "Cine de Autora” presenta a una mujer directora de cine que ha sido premiada en diversas ocasiones: Mary-Beatrix Mugishagwe, que rueda la realidad africana con "amor y 
humor", porque no se pueden cerrar los ojos ante lo que tenemos delante. Un cine comprometido que, en su caso, además de arriesgado, ha sido premiado. Hablar de cine comprometido en España, como el hecho de tener a estas mujeres entre nosotras, produce una cierta melancolía porque es algo que hemos venido olvidando. Se echa de menos el coraje y la fuerza viva de estas mujeres que tienen un largo recorrido por hacer pero que, si se montan en el carro adecuado, lo harán pronto y bien.

El noveno artículo firmado y segunda semblanza trae una periodista y presentadora comprometida de TV: Marie Ange Mushobekwa. Se queja de que la dependencia marital en el Congo es muy fuerte. Ella es muy privilegiada y debe agradecer a su marido estar donde ésta. Si él no quisiera, ella no podría ni salir de casa. Ciertamente ahí la mujer africana tiene un trecho que recorrer, pero a la mujer española esto no le suena tan extraño. En la dictadura franquista esto también era así en España. No así es el porcentaje de mujeres violadas en las zonas de conflicto, un porcentaje espeluznante: 60 por ciento. La cifra no sólo pone los pelos de punta sino que exige una actuación política externa. La ONU tiene mucho más trabajo que hacer de lo que sería deseable.

El décimo artículo, también firmado, y tercera semblanza africana, nos presenta a la Única juez del Supremo, que además es su título. Aloma Mukhtar, magistrada de 62 años, es fuerte y optimista. Piensa que las mujeres pueden desarrollarse sólo con mucho trabajo, determinación e infinidad de paciencia. Para ella, como juez, el gran problema es la coexistencia del código civil y el islámico y la prevalencia en muchos casos del último. Erradicarlo va a ser difícil, pero no tira la toalla. Está convencida de que hay que seguir luchando.

El undécimo artículo, presenta la cuarta semblanza, igualmente firmada. Se trata de Trinidad Morgades, vicerrectora de la universidad en Guinea Ecuatorial. De los mil matriculados en la universidad, sólo 60 estudiantes son mujeres. Unas cifras absolutamente diferentes a las españolas en este momento, pero no tan lejanas en la historia de la universidad española. Ella, que no se siente discriminada negativamente, considera que hay que seguir luchando. Una mujer eminentemente práctica que dice que no hay que inventar la pólvora, sino simplemente observar las experiencias que van bien. Todas ellas transmiten fuerza y energía, algo que en mi opinión, a veces las mujeres europeas vamos perdiendo en aras de la democracia y de formas demasiado civilizadas a veces. Las mujeres africanas tienen bastante más que enseñar que las españolas a ellas.

Este duodécimo, y también firmado, ofrece la crónica de la aprobación del Senado de la Ley de Igualdad. El título destaca la feliz coincidencia de la aprobación de la ley la víspera del 8-M. Lamenta que el PP no votara a favor de la ley y contempla dos aspectos de la ley que no han tocado el resto de los periódicos: la creación de 43 juzgados de violencia doméstica así como el tema de las cuotas y cómo afectarán éstas a las listas electorales. A partir de ahora, 40\% de los candidatos deberán ser mujeres, en tramos de 5 . Está bastante más elaborado que las noticias de agencias.

El artículo 13, toca un aspecto que no ha sido tratado por el resto de los 
periódicos. Se refiere a las multas, de hasta 90.000 euros, que deberán pagar las empresas por actitudes discriminatorias hacia sus trabajadoras. La contrapartida al castigo de la multa está en que las empresas que ejerzan una discriminación positiva tendrán prioridad a la hora de recibir cualquier prestación por parte de la Administración Pública. Se incentiva así la discriminación positiva y se va acabando con la discriminación negativa. Este aspecto, poco comentado por el resto de los periódicos trae aparejado un cambio de mentalidad por parte de los empresarios porque obviamente coloca a sus empresas en una posición de ventaja frente a las que muestren actitudes empresariales poco respetuosas con la Ley de Igualdad.

El número 14 es otro artículo que habla de la Ley de Igualdad, y más concretamente de la baja maternal, según reza su título. Para gloria de EL PAÎ́S toca un aspecto también poco comentado, como es que las madres que no hayan cotizado lo suficiente, también tendrán derecho a un nuevo subsidio que no existía con anterioridad a la Ley de Igualdad.

El artículo número 15 retoma un aspecto que tampoco había sido comentado, la cuota del $40 \%$ de aplicación a los colectivos de poder, y con especial incidencia en las listas electorales. A partir de la aplicación de la Ley de Igualdad, no podrá estar representado ninguno de los sexos en menos del $40 \%$ ni más del $60 \%$, para mantener una igualdad real. Obsérvese que en todos los casos de los artículos de EL PAIÍS que traen a colación la Ley de Igualdad los aspectos que se toman están tratados siempre desde un punto de vista positivo, destacando aspectos positivos y en un tono muy constructivo de la nueva realidad social española.

El artículo dieciséis titulado "Manos femeninas atizan el carbón” es uno de los artículos más originales y a la vez mejor documentados, en realidad de un caso de discriminación. La autora lo escribe con algunas pinceladas más poetizadas que el resto de los artículos de género, crónica o comentario. Con motivo de un caso de discriminación femenina, la autora relata la génesis y la evolución de una empresa de carácter familiar que ha evolucionado considerablemente hasta ponerse a la cabeza de las empresas que han optado por una renovación mental empresarial. Muy posiblemente, dentro de poco el cargo de la Dirección de Recursos Humanos lo ocupará una mujer, y ya algunos puestos que antes ocupaban trabajadores varones, son ahora las manos femeninas las que atizan el carbón.

El último tema referido al 8-M es la viñeta de Forges. No en vano utiliza un lenguaje humorístico. Esta esposa, sorprendida (se está cayendo de espaldas) y regocijada, y no es para menos. El varón aparece con un gran corazón que lo comparte todo, esa es la verdadera igualdad, lo que constituye un broche de oro para cerrar el tema del 8-M.

6.3.4. LA RAZÓN. Este primer artículo titulado "En femenino plural”, plantea un breve y conciso texto periodístico que propone desterrar todo tipo de demagogias, desde perspectivas plurales, por la dignidad y la igualdad. Es serio y ponderado pero no presenta nada destacable.

El segundo título "La mujer en Afganistán”, escrito por el embajador de Estados Unidos en España, Eduardo Aguirre, hace un panegírico del papel de la intervención del presidente Bush junto con el presidente afgano Karzai, al firmar el Consejo de 
Mujeres Afgano-Estadounidenses. Aunque habla del avance de la mujer afgana, en realidad lo que está haciendo en ensalzar la firma del Consejo. Según él, desde que en 2002 se firmara este convenio, la situación de la mujer es absolutamente distinta, y claro está mejor. El tono del artículo de opinión suena a autobombo, algo que no sería deseable, porque, además de lamentable por las mujeres, sería una contaminación de la opinión pública española.

El tercer artículo, titulado "El futuro de África tiene nombre de mujer”, en realidad es una gran fotografía en cuyo centro figura la Reina Sofia. Es un bonito titular para una bonita e histórica foto, pero nada más. El periódico no establece ninguna vinculación ni implicación con la jornada reivindicativa del 8- $M$, dado que sólo presenta una fotografía.

El cuarto artículo presenta un extraño titular. En lugar de hablar de lo conseguido en la Ley de Igualdad en el momento de su publicación en el BOE habla del futuro (2013) como si fuera una noticia de implicación próxima. Resulta poco directo y positivo. De hecho, las noticias y/o sus titulares que hablan de hechos que se producirán 6 años más tarde no son noticias, son otra cosa. El autor, P. Manzano, debería haber releído su trabajo antes de publicarlo: Resulta un tanto ambiguo, y con intencionalidad oscura.

\subsection{Item especial: La Reina.}

La Reina no aparecía inicialmente entre los puntos a analizar, pero dadas las circunstancias de aparición, su figura (como actora social, que no actriz) ha ido tomando cuerpo, importancia y relevancia a la hora de analizar los contenidos mediáticos del 8-M, se aprecia que, la Reina, lejos de ser un ítem de interés sólo para los periódicos de marcada tendencia monárquica, se ha manifestado como un centro de interés para todos ellos. Dicho de otra forma: la Reina, en lugar de ser un ítem diferenciador en función de las tendencias ideológicas de los diferentes medios de comunicación, se convierte en un elemento unificador, que puede ser incluso un elemento cohesionador de gran valor político y social. El hecho de que la Reina aparezca en un acto o evento del tipo que sea, y por tanto aparezca en una fotografía, puede transformarlo. Tiene la facultad de convertir un acto privado o social, en un acto público de marcado interés periodístico para todos los periódicos sin excepción.

\section{Referencias bibliográficas}

DADER, José Luis: (1992): “La canalización o fijación de la “agenda” por los medios”. Opinión Pública y Comunicación Política, Madrid, Eudema Universidad, de Alejandro Muñoz Alonso, et. al.: 294-316.

- (2000): "La "mujer" como categoría emergente en la producción de las noticias:pros y contras deuna nueva visibilidad periodística”. Cuadernos de Información y Comunicación, $\mathrm{n}^{\circ}$ 5, pp. 23-37.

LEÓN, José Luis (1996): Los efectos de la publicidad. Barcelona, Ariel.

McCOMBS, M., \& SHAW, D.L. (1972): "The agenda-setting function of the mass media”. Public Opinion Quarterly, 36: 176-185. 
VAN DIJK, Teun A (1990): La noticia como discurso. Comprensión, estructura y producción de la información. Barcelona, Paidós Comunicación. Título original: News as Discourse, Lawrence Erlbaum Associates, Publishers. Traducción de Guillermo Gal. 